\title{
EXPERIÊNCIAS NAS ESCOLAS ÉTNICAS RURAIS NO SUL DE SANTA CATARINA NO CONTEXTO DO PROCESSO DE NACIONALIZAÇÃO DO ENSINO
}

\author{
EXPERIENCES IN RURAL ETHNIC SCHOOLS IN THE \\ SOUTH OF SANTA CATARINA WITHIN THE CONTEXT OF \\ EDUCATION AND ITS NATIONALIZATION
}

\author{
Giani Rabelo* \\ Marli de Oliveira Costa**
}

\begin{abstract}
Resumo: Abordaremos alguns aspectos da cultura escolar de duas escolas instaladas por imigrantes europeus, no início do século XX, em localidades rurais do Sul de Santa Catarina. Trata-se das escolas "Núcleo Hercílio Luz" e "Casemiro Stachurski", mantidas, inicialmente, por núcleos de imigrantes italianos e poloneses, respectivamente. Nos anos de 1930 estes estabelecimentos foram assumidos pelo poder público estadual e, mais tarde, nos anos de 1990, pelo poder municipal. Ao mergulharmos nas histórias destas duas instituições escolares, buscamos, principalmente, compreender as experiências vivenciadas pelos sujeitos - alunos e alunas - no processo de nacionalização do ensino, a partir das práticas pedagógicas que ali foram instituídas e articuladas. A pesquisa ocorreu a partir de fontes documentais e fontes orais. Os documentos orais, produzidos a partir de entrevistas com antigos/ as alunos e alunas, foram construídos a partir da metodologia da história oral. No princípio, as aulas aconteciam nas casas ou em locais cedidos pelos próprios moradores. O quadro docente era formado por aqueles/as que dominavam a leitura e a escrita na língua dos imigrantes e ensinavam seus filhos e filhas. Com o processo de nacionalização do ensino, principalmente no Estado Novo do Governo Vargas, os docentes foram afastados e substituídos por outros que falavam e ensinavam em língua portuguesa. Essas escolas abrigaram diferentes experiências, marcadas pelas culturas dos distintos grupos de imigrantes, mas, além disso, reconstruíram culturas dentro e fora do ambiente escolar.
\end{abstract}

Palavras-chave: Escola Rural. Escola Étnica. Nacionalização do Ensino.

* Professora no Programa de Pós-Graduação em Educação e do Curso de Pedagogia da Universidade do Extremo Sul Catarinense (UNESC). E-mail: gra@unesc.net

** Professora no Programa de Pós-Graduação em Educação e nos cursos de Pedagogia e História da Universidade do Extremo Sul Catarinense (UNESC). E-mail: moc@unesc.net 


\begin{abstract}
It is the schools "Núcleo Hercílio Luz" and "Casimir Stachurski" maintained initially by nuclei of Italian and Polish immigrants, respectively. In the 1930s these institutions were made by state government and, later, in the 1990s, the municipal government. When studying the histories of these two schools, we seek primarily to understand the experiences of the subjects - male and female students - in the process of nationalization of education, from teaching practices that have been established there and articulated. The research occurred from documentary sources and oral sources. The oral documents, produced from interviews with former students, were constructed using the methodology of oral history. In principle, the classes took place in homes or places assigned by the residents themselves. The teaching staff consisted of teachers, ie those that dominated the reading and writing in the language of immigrants and taught their sons and daughters. With the nationalization process of teaching, mainly in the New State Government Vargas, teachers were dismissed and replaced by teachers who spoke and taught in Portuguese. These schools harbored different experiences, marked by the cultures of the different groups of immigrants, but also rebuilt cultures within and outside the school environment.
\end{abstract}

Keywords: Rural School. Ethnic School. Nationalization of Education.

\title{
INTRODUÇÃO
}

Este artigo é resultado do trabalho efetuado pelo Grupo de Pesquisa em História e Memória da Educação (Grupehme), vinculado à Universidade do Extremo Sul Catarinense (Unesc) desde 2001. Dentre as atividades do grupo de pesquisa destacam-se a construção de um banco de dados sobre o processo de educação em Santa Catarina ao longo do século XX, e a publicação da Série Cadernos da História da Educação em Criciúma, que registra a história das escolas mais antigas da rede municipal de educação de Criciúma ${ }^{1}$, bem como a implantação do Centro de Memória da Educação do Sul de Santa Catarina - CEMESSC (virtual). ${ }^{2}$

Criciúma se apresenta como cidade referência no cenário sulcatarinense. Isso se dá em virtude das relações econômicas e sociais que vêm se desenvolvendo ao longo de sua história. A região onde, atualmente, está circunscrita foi colonizada por imigrantes italianos, poloneses e alemães, a partir de 1880. A partir desta época até a implantação do Estado Novo de Getúlio Vargas (1937), a educação dos filhos e filhas dos imigrantes ou descendentes era garantida por uma organização comunitária, dando início as primeiras experiências escolares. As próprias comunidades mantinham as escolas e professores/as para ensinar seus filhos e filhas a ler e escrever e em alguns casos os governos ou instituições dos países de origem subsidiavam estas iniciativas. Estas duas modalidades de escolas comunitárias foram apontadas em alguns registros. Mário Belolli, memorialista criciumense, escreveu em um artigo para o jornal Tribuna Criciumense, em abril de 1972, que os moradores de 
Primeira Linha, um dos bairros da cidade, a exemplo de outras localidades de Criciúma, preocupados com a educação das crianças, contrataram um professor italiano de nome Fermo Antea para lecionar. Assim, em 1894, inaugurou-se a primeira escola nessa localidade. O professor recebia alimentos em troca dos serviços. Pedro Milanez, em seu livro "Fundamentos Históricos de Criciúma"3, cita as primeiras escolas e os primeiros professores na cidade, lembra que as primeiras escolas, em 1902, eram mantidas pelo governo italiano e, depois, em 1906, chegaram à cidade Irmãs de Caridade vindas de São Paulo para lecionar. D. Bersábia Sonego recorda que essas Irmãs ensinavam em uma cartilha que tinha uma página em português e outra em italiano, os conhecidos sillabários. ${ }^{4}$ Estudos precisam ser empreendidos para que se possa compreender, de forma mais detalhada, como se deu a manutenção das escolas organizadas para filhos e filhas de imigrantes.

As escolas que seguiram após essas iniciativas comunitárias foram fechadas ou assumidas pelo governo catarinense durante o Estado Novo de Getúlio Vargas, em consonância com o que ocorreu em outras regiões do país. Mais tarde, tornaram-se de responsabilidade do município, uma vez que “[...] na década de 1990, as escolas estaduais de menor porte e de zona rural vivenciaram parte de um processo de municipalização do Ensino Fundamental [...]".5

A Era Vargas, que vai de 1930 até 1945, introduziu muitas mudanças no sistema educacional brasileiro e uma delas afetou profundamente as escolas organizadas por imigrantes ou descendentes de imigrantes, em maior número as dos europeus por serem o maior contingente. Foi a campanha de nacionalização do ensino, intensificada no Estado Novo (1937-1945), que previu uma série de estratégias para diminuir a influência das comunidades de imigrantes e obrigar a integração delas à população brasileira. Tinha-se como premissa a construção da nacionalidade e exaltação da brasilidade, com o intuito de avivar o sentimento de nação nos brasileiros, mas acima de tudo, impor uma identidade nacional aos imigrantes. ${ }^{6}$

Entretanto, em Santa Catarina, a campanha de nacionalização do ensino já vinha dando seus primeiros passos desde 1911, no governo de Vidal Ramos, tendo como representante direto o Inspetor Geral do Ensino Orestes Guimarães, que exerceu a função até 1931, quando veio a falecer. ${ }^{7}$ Nesse processo, o sul de Santa Catarina por ter sido habitado por imigrantes europeus provindos da Itália, Alemanha e Polônia foi um dos principais alvos.

Neste artigo abordaremos alguns aspectos da cultura escolar de duas escolas instaladas por imigrantes europeus, no início do século $\mathrm{XX}$, em localidades rurais do sul de Santa Catarina, mais precisamente em Criciúma. Trata-se das escolas "Núcleo Hercílio Luz" e "Casemiro Stachurski", mantidas, inicialmente, por núcleos de imigrantes italianos e poloneses, respectivamente. Destacamos nessas experiências três questões: as dificuldades do contato e da aprendizagem com uma língua diferente da falada em casa, ou seja, a língua 
italiana e polonesa; o problema da conciliação entre o trabalho na roça e a frequência escolar e, por último, os castigos escolares.

Ao nos perguntarmos sobre por que fazer a história das instituições escolares, buscamos a resposta em Sanfelice ao afirmar que:

Os historiadores, dentre outras razões, apontam que suas preocupações não são apenas as de registrar o passado e/ou o presente, por meio de uma narrativa baseada em fontes, mas de compreender e interpretar a própria educação praticada em uma dada sociedade e que se utiliza das instituições escolares, como um espaço privilegiado para executá-la. A singularidade das instituições educativas mostra e esconde como ocorreu e/ou ocorre o fenômeno educativo escolar de uma sociedade. Mergulhar no interior de uma Instituição Escolar, com o olhar do historiador, é ir em busca das suas origens, do seu desenvolvimento no tempo, das alterações arquitetônicas pelas quais passou, e que não são gratuitas; é ir em busca da identidade dos sujeitos (professores, gestores, alunos, técnicos e outros) que a habitaram, das práticas pedagógicas que ali se realizaram, do mobiliário escolar que se transformou e de muitas outras coisas. ${ }^{8}$

Ao mergulharmos nas histórias destas duas instituições escolares, buscamos, principalmente, compreender as experiências vivenciadas pelos sujeitos - alunos e alunas - no processo de nacionalização do ensino, a partir das práticas pedagógicas que ali foram instituídas e articuladas.

\section{CONTEXTUALIZANDO AS ESCOLAS ÉTNICAS RURAIS: "NÚCLEO HERCÍLIO LUZ” E “CASEMIRO STACHURSKI"}

As escolas investigadas nesse artigo pertencem atualmente à Rede Municipal de Ensino da Cidade de Criciúma/SC. A Escola "Núcleo Hercílio Luz", situa-se no bairro Morro Estevão e a Escola "Casemiro Stachurski” está localizada no bairro de Linha Batista. Ambas emergiram com caráter particular/ comunitário e étnico, além de estarem localizadas em áreas consideradas rurais à época da implantação. Os/as primeiros/as professores/as desses estabelecimentos recebiam, em troca do ensino ministrado às crianças, casa para morar e alimentação. Outra característica comum entre os dois estabelecimentos é que os/as primeiros/as professores/as ministravam aulas na língua de origem dos imigrantes que ocupavam as respectivas localidades, ou seja, o ensino em língua italiana na Escola Núcleo Hercílio Luz e em língua polonesa na Escola "Casemiro Stachurski", estabelecendo, desse modo, o caráter étnico das escolas. Os consulados, italiano e polonês, contribuíam financeiramente 
para o pagamento do salário dos/as professores/as. Nos anos de 1930 essas escolas passaram a ser administradas pela Rede Estadual de Ensino de Santa Catarina e nos anos de 1990, foram municipalizadas.

Para reconstruir as trajetórias destes educandários os membros do Grupo de Pesquisa História e Memória da Educação (Grupehme) pesquisaram em fontes documentais encontradas em seus acervos, como: atas das reuniões do Círculo de Pais e Mestres, livros termos de visitas dos inspetores de ensino, livros de matrícula, livros de atas do Caixa Escolar, notícias de jornais envolvendo a criação das escolas e decretos de nomeação de professores/as, fotografias e, além disso, memórias daqueles primeiros alunos/as, professores/ as e funcionários/as. Como resultados desse trabalho foram publicados dois cadernos: "A Escola na Colina: Grupo Escolar Núcleo Hercílio Luz (19052002)", no ano de 2004 e "Casemiro Stachurski: Das aulas particulares/ comunitárias ao ensino público municipal”, em 2005. Os eixos que nortearam a sistematização dos cadernos versaram sobre a organização das comunidades e das escolas; o trabalho docente; currículo e práticas pedagógicas e, por último, as experiências dos alunos e alunas em seus tempos escolares. A partir destes trabalhos sentimos a necessidade de aproximar estas duas experiências, a fim de perceber suas singularidades, na perspectiva dos alunos/as.

É preciso observar que os arquivos escolares são escassos, não existe o hábito da guarda da materialidade produzida nas escolas. Cadernos de planos de aula são descartados todos os anos, muitas escolas queimam papéis antigos com a justificativa de que são "velhos". Nos estabelecimentos investigados encontramos alguns documentos antigos e por deles pudemos, cotejando-os com outras fontes, reconstruir um pouco da trajetória dessas escolas. Mas, mesmo encontrando vários documentos que resistiram às intempéries, a condição de guarda e preservação destes não ocorre adequadamente, favorecendo a deterioração e o descarte dos documentos. Percebemos que um dos principais elementos causadores dessa atitude é a falta de conhecimento, somando-se a isto a ausência de uma política pública voltada para essa questão.

\section{BUSCANDO OUTRAS FONTES: O USO DA HISTÓRIA ORAL}

Como já mencionado, além das fontes documentais, pesquisamos também fontes orais. Os documentos orais foram construídos a partir da metodologia da história oral. Em comunidades cuja história corre o risco do esquecimento com morte daqueles que assumiam o papel de "guardiões", lembrando e narrando os processos que tais comunidades passaram ao longo do tempo, a história oral apresenta-se como alternativa à história oficial, que valoriza apenas os documentos escritos como fontes "verdadeiras" para a consulta histórica como analisa Meihy. ${ }^{9}$ Assim, sabe-se que muitos trabalhos 
têm utilizado a história oral como alternativa para garantir o registro da história de comunidades e culturas, como o trabalho sobre as lembranças de migração de Alistair Thomson ${ }^{10}$, ou o estudo sobre os ex-combatentes de Michael Pollak. ${ }^{11}$ Autores que possibilitaram compreender os esquecimentos.

No entanto, é necessário destacar que a participação do/a pesquisador/a junto a seus narradores durante as entrevistas é fundamental na produção do documento, embora como discute Antoinette Errante: "os narradores não somente escolhem o que vão rememorar e contar a você, eles também participam negociando o contexto da rememoração" ${ }^{12}$, quem finaliza o documento é o pesquisador/a. Nesse sentido Amado coloca a importância da "ética em história oral". ${ }^{13}$ Os depoimentos, devem retornar aos narradores/as transcritos para que se possa tomar as devidas precauções quanto à autorização de seu uso.

Em história da educação, a história oral também tem se apresentado. Ao defender o uso da história oral nas pesquisas em história da educação, Antoniette Errante afirma que

As histórias orais acrescentam uma dimensão não-oficial inestimável para essa história educacional que, de outro modo, se encontra disponível apenas através da leiturae contra-leitura- da documentação oficial dos regimes coloniais e pós - coloniais. As histórias orais podiam contribuir com essa dimensão acrescentando a história como experiência vivida. ${ }^{14}$

O cruzamento das fontes documentais e orais foi algo presente em todo momento da investigação sobre os dois educandários. Lopes e Galvão, sobre este procedimento metodológico, afirmam que:

O cruzamento e confronto das fontes poderá também ajudar no controle da subjetividade do pesquisador. É uma operação indispensável. Há uma expressão antiga que diz bastante do incansável trabalho que se há de ter com o entretecer do problema, com as questões formuladas e a ida às fontes: "da bigorna à forja, da forja à bigorna". ${ }^{15}$

Os documentos pesquisados apresentaram-se, nas palavras de Eclea Bosi, como "objetos biográficos", ou como um lugar para ancorar memória, sendo esta individual e coletiva, que ao serem articulados com as lembranças de antigos/as professores/as e alunos/as, nos ajudaram a tecer partes da trajetória destas escolas e, consequentemente, contribuíram para a compreensão da história da educação no município de Criciúma, principalmente daquelas escolas que iniciaram como particulares/comunitárias e étnicas. ${ }^{16}$ 


\section{COMPREENDENDO O PROCESSO ESCOLAR ÉTNICO EM MORRO ESTEVÃO E EM LINHA BATISTA}

A trajetória desses educandários compõe o cenário histórico da escola pública catarinense, porém com suas particularidades e especificidades. Para entendê-las é necessário, em um primeiro momento, situar a construção das escolas particulares/comunitárias, chamadas também por alguns pesquisadores de escolas étnicas.

Entende-se por "escolas étnicas" aquelas criadas para os filhos e filhas de imigrantes europeus que chegaram ao Brasil no decorrer do século XIX e que funcionaram até o início do Estado Novo de Getúlio Vargas. De acordo com Kreutz, o processo escolar étnico não constituiu uma ação comum entre todas as levas das distintas etnias. $\mathrm{O}$ autor ressalta que:

Os alemães, italianos, poloneses e japoneses, ao se
estabelecerememáreas rurais formandonúcleos populacionais
com características e estruturas marcantemente étnico-
culturais, tiveram maior visibilidade enquanto imigrantes
e promoveram as escolas elementares comunitárias.
Estas escolas tinham uma conotação fortemente étnica
e, com exceção das escolas japonesas, também uma
conotação fortemente confessional cristã. Além destas
escolas comunitárias, houve um número significativo de
escolas particulares mantidas por congregações religiosas,
masculinas e femininas, geralmente em área urbana,
mantendo especificidades étnicas do país de origem da
mantenedora. Os imigrantes também tiveram escolas étnicas
particulares laicas, em área urbana, mas em menor número
que as anteriores. Diversas destas escolas particulares, tanto
as de congregações religiosas como as laicas, tornaram-
se conhecidas como centros de excelência no ensino de
primeiro e segundo graus. ${ }^{17}$

A ocupação pelos imigrantes, no sul da província de Desterro, iniciou-se em 1877, primeiramente pelos italianos, seguidos dos poloneses e dos alemães. Após chegarem em Desterro desceram até Laguna e Tubarão, estabelecendose nas proximidades dos rios e ali fundaram os primeiros núcleos coloniais. ${ }^{18}$ Posteriormente, outros núcleos foram sendo organizados, entre eles o dos italianos, denominado de Núcleo Hercílio Luz, em Morro Estevão, e o de poloneses, na Linha Batista, ambos situados na cidade de Criciúma, que, à época, pertencia ao município de Araranguá.

O bairro Morro Estevão, que, anteriormente, tinha a denominação de Núcleo Hercílio Luz, talvez seja o local em que tenha ocorrido uma das primeiras experiências de educação formal em Criciúma, pois encontramos registros 
com datas de 1905 que versam sobre atividades escolares, mencionando, por exemplo, que um professor de origem italiana recebia proventos da própria comunidade para ensinar as crianças. Em 1913, essa mesma comunidade faz um abaixo-assinado ao então governador de Santa Catarina, Hercílio Luz, para terem uma escola pública. Escola que se concretiza, porém, a data exata não foi possível precisar, mas uma ata de visita do inspetor de ensino nos dá uma pista importante, ou seja, a data de $1925 .{ }^{19}$

A localidade de Linha Batista, por sua vez, foi colonizada por imigrantes poloneses, a partir de 1891, e as experiências com a educação escolar dos filhos e filhas desses imigrantes deram-se a partir do início do século XX. Sobre isso, o Sr. Casimiro Tibincoski conta que a maioria dos imigrantes poloneses era alfabetizada na própria língua. Mesmo sem condições de construir um estabelecimento escolar, as crianças eram reunidas em casas particulares para receberem as primeiras instruções e, como não tinham trazido nenhum profissional da educação, os educadores eram escolhidos entre os que sabiam mais e, assim, assumiram a educação os senhores João Machinski e Gabriel Bartosiak, no início. ${ }^{20}$

Em casas particulares, ensinadas por moradores que se tornavam professores/as por saberem as "letras" e as "contas" um pouco mais que os outros moradores; ou agrupadas em classes escolares multisseriadas, acompanhadas por professores/as pagas pelo Estado a partir de 1920, essas crianças adquiriam outro "lugar" - o lugar de aluno e aluna. A idade de ir à escola apresenta-se na vida das crianças como um rito de passagem, ou seja, outra instituição, diferente da família e da igreja, passa a fazer parte de suas vidas. Assim, as atividades escolares deveriam ser sua principais atribuições. Alguns autores chamam de "ofício de aluno". ${ }^{21}$ Em que isso interferiu em suas vidas? Como veêm essas experiências? Que lembranças significativas permaneceram em suas memórias?

\section{EXPERIÊNCIAS DE ALUNOS/AS NAS ESCOLAS ÉTNICAS RURAIS DE CRICIÚMA (SC)}

Buscar as experiências de alunos/as na infância a partir das memórias dos adultos é lidar com a "dialética da lembrança e do esquecimento", como coloca o historiador Pierre Nora. ${ }^{22}$ Ao lidar com lembranças e esquecimentos, vamos dando sentido aos acontecimentos que ficaram arquivados nas lembranças, mas como afirma Alistair Thomson, os sentidos que damos às nossas memórias mudam com o passar do tempo na medida em que:

Experiências novas ampliam constantemente as imagens antigas e no final exigem e geram novas formas de compreensão. A memória 'gira em torno da relação passado- 
presente, e envolve um processo contínuo de reconstrução e transformação das experiências relembradas', em função das mudanças nos relatos públicos sobre o passado. [...]. As histórias que relembramos não são representações exatas do nosso passado, mas trazem aspectos desse passado e os moldam para que se ajustem às nossas identidades e aspirações atuais. ${ }^{23}$

Evocadores como fotografias e outros colegas ajudaram a tecer a difícil tarefa de encontrar os fazeres dos alunos/as no passado, uma vez que, nas escolas, pouco ou nada foi guardado de documentação. Como desenhavam as crianças dessas escolas? Como eram suas letras? O que escreviam? Que registros deixaram de suas passagens pela escola? Perguntas que dificilmente se pode responder.

Cem anos nos afastam da primeira experiência escolar dessas comunidades, dos registros encontrados nas escolas, a data mais longínqua é em Morro Estevão, 1905. Dos pertences dos alunos/as, 23 livros de leitura em italiano e polonês que variam de 1928 a 1950; de suas lembranças, as que mais significaram. Apoiados nessas fontes, fizemos algumas aproximações vivenciadas por esses alunos/as. Seguindo a linha de raciocínio de Rolnik, a escola se apresenta como um "espaço vivido". A ideia de "espaço vivido" busca perceber os/as alunos/as dentro de relações que envolvem um "lugar". ${ }^{24}$

Nesse processo de aproximação das experiências escolares, o conceito de cultura escolar foi fundamental. Como Viñao Frago, compreendemos que a cultura escolar configura-se como um conjunto de ideias, princípios, critérios, normas e práticas sedimentadas ao longo do tempo das instituições educativas, uma vez que, no interior delas, são produzidas maneiras de pensar e de agir, que propiciam aos envolvidos nas práticas escolares "estratégias e pautas para desenvolver tanto nas aulas como fora delas", atitudes, modos de vida e de pensar, materialidade física, hábitos, objetos e ritos escolares. ${ }^{25}$

Três questões aparecem de forma bastante significativa nas experiências escolares dos/as ex-alunos/as: as dificuldades do contato e da aprendizagem com uma língua diferente da falada em casa, a língua italiana e polonesa; o problema da conciliação entre o trabalho na roça e a frequência escolar e, por último, os castigos escolares.

\section{IDADE DE TORNAR-SE ALUNO E ALUNA E O TRABALHO NA ROÇA}

A idade dos/as alunos/as irem para a escola, de acordo com os depoimentos, variava entre 8 e 13 anos, sendo que Casimiro Tibincoski, nascido em 1917, recorda que, em Linha Batista, não aceitavam jovens com 14 anos. ${ }^{26}$ 
Os depoentes permaneceram na escola por, no máximo, três anos. Alguns fatores implicaram nesse tempo de permanência, dois deles estão ligados ao fato de que as escolas funcionavam até a $3^{\mathrm{a}}$ série de forma multisseriada, ou seja, $1^{\text {a }}, 2^{\mathrm{a}}$ e $3^{\mathrm{a}}$ séries juntas sob a responsabilidade de um/uma professor/a; e o trabalho na agricultura. Este envolvia toda a unidade familiar, o que implicava a contribuição das crianças. "Naquele tempo, os pais mandavam dois, três anos, depois tiravam a criança e botavam na roça", lembra o Sr. Casimiro Tibincoski. ${ }^{27}$

Em Morro Estevão, João Zanette, nascido em 18/5/1911, iniciou com 8 anos e concluiu com 10 anos e diz: "a única coisa que aprendi na escola foi fazer conta". D. Maria de Luca, nascida em 1923, iniciou com 11 anos, pois como coloca: "uma vez mandavam velha, 11 anos, e eu trabalhava na roça". Por esse motivo, D. Maria fez apenas até o " $2{ }^{\circ}$ ano". ${ }^{28}$ Dona Maria Dinca Dal'Toé, nascida em 1915, foi para a escola com 13 anos de idade. Para recordar o porquê dessa idade, ela vasculhou suas lembranças, encontrando o trabalho na roça. E atualizou suas lembranças comparando com o tempo presente em que a lei determina a idade de ingresso na escola. ${ }^{29} \mathrm{~A}$ esse respeito Myriam Moraes de Lins Barros, ao estudar lembranças de família a partir das recordações dos avós, coloca que:

Os limites de sua infância são traçados, no presente, com olhos e elaborações atuais que, embora possam ser explicados e racionalizados em função das mudanças sociais, mudaram as representações dessas pessoas, aparecendo em cada etapa de sua vida com configurações diferentes. ${ }^{30}$

Além do trabalho na roça relembrado pelos narradores/as, os registros realizados pela professora Paula Westphal, que lecionou na escola de Morro Estevão entre os anos de 1925 e 1939, oferecem, entre outras, informações sobre a reprovação dos alunos e das alunas: Em 1925, dos 45 alunos do $1^{\circ}$ ano, foram reprovados 20; em 1926, dos 44 alunos do $1^{\circ}$ ano, foram reprovados 16; em 1927, dos 36 alunos foram reprovados 14 e, em 1932, dos 51 alunos reprovaram 15. O número de reprovações diminuiu de $1935 \mathrm{em}$ diante. A evasão escolar também é notável nesse período. Em 1925, dos 45 alunos que frequentaram o $1^{\circ}$ ano, apenas oito seguiram para o $2^{\circ}$ ano em 1926, desses oito, três seguiram para o $3^{\circ}$ ano em 1927. Em 1928, dos 32 alunos que frequentavam o $1^{\circ}$ ano, seis foram para o $2^{\circ}$ ano em 1929 , sendo que permaneceram seis no $3^{\circ}$ ano de 1930. Em 1931, havia 56 alunos matriculados no $1^{\circ}$ ano, foram para o $2^{\circ}$ ano de 1932 apenas 13 alunos e, para o $3^{\circ}$ ano de 1933, oito. Esses números seguem mostrando a evasão do $1^{\circ}$ ano para o $2^{\circ}$, e uma razoável permanência entre o $2^{\circ}$ e o $3^{\circ}$ ano até 1939 , de acordo com os registros guardados na escola.

A evasão escolar pode estar ligada à reprovação, fator que incide sobre o tempo de permanência na escola. Em Linha Batista, não conseguimos, pelos 
documentos a que tivemos acesso, estabelecer o mesmo quadro de índices de aprovação e reprovação.

\title{
A FALA E A LÍNGUA NA ESCOLA
}

A língua portuguesa tornou-se obrigatória nas escolas do Brasil durante o Governo do Estado Novo (1937-1945), tempo em que os/as filhos/as de imigrantes italianos e poloneses das localidades investigadas mais sofreram na escola, pois, em casa, a língua falada era a italiana ou a polonesa e, na escola, a professora ensinava em português.

Antônio Zanette, que concluiu o $3^{\circ}$ ano em 1937, conta que:

\begin{abstract}
Naquele tempo era assim, tinha turma que só falava em italiano, e ela [a professora] queria dar aula em brasileiro, português. Mas eu não compreendia nada como era, então ela ficava brava, e a gente falava em italiano para cá e para lá. $^{31}$
\end{abstract}

Os irmãos Casemiro e Tereza Demboski, nascidos em 1918 e 1919, relatam que, ao entrarem na escola, só falavam em polonês, segundo eles: " $\mathrm{A}$ professora que dava aula para nós tinha dificuldade. Nós queríamos contar alguma coisa, alguma briga para ela, mas ninguém sabia falar". ${ }^{32}$ Há indícios de que esse processo de interdição da língua permaneceu por muito tempo, uma vez que Alberto Rrzatki, nascido em 1949, recorda que:

o primeiro ano eu não sabia falar em português, sorte que eu ia acompanhado do meu irmão, ele estava na $3^{\mathrm{a}}$ série e ele falava em português e eu não. A professora tinha que ter uma ginga para trabalhar com isto tudo, geralmente o aluno que entrava na $1^{\text {a }}$ série não falava português. ${ }^{33}$

Os silabários apresentaram-se como alternativas para o ensino da língua portuguesa nas chamadas colônias desde o início do século XX, pois havia o entendimento por parte dos imigrantes de que era necessário aprender o português, no entanto, isso não excluía a língua de seu país de origem, provavelmente as crianças tornavam-se bilíngues. Encontramos um exemplar, que nos foi doado por João Zanette, ex-aluno de Morro Estevão, onde em uma página se escreve em italiano e, na outra, o mesmo texto em português.

Não encontramos silabários em polonês e português, mas uma experiência particular de Linha Batista era o professor que ensinava nas duas línguas, assim as crianças, em um período, estudavam em português e, no outro, em polonês: "Eu estudei aqui na Linha Batista, com Casemiro Stachurski. 
Estudava de manhã em brasileiro e, de tarde, em polonês", recorda D. Pelaguia Marchiski Bartosiak, nascida em 1927. ${ }^{34}$

A ausência de vestígios materiais sobre o trabalho pedagógico realizado pelos professores poloneses não implica na inexistência desses materiais bilíngues. Kreutz afirma que os imigrantes poloneses também elaboraram seus próprios materiais didáticos. "O primeiro foi o Manual para as escolas polonesas no Brasil, de Jerônimo Durski, em 1893. A primeira parte do manual é uma cartilha de alfabetização em polonês, no método silábico. A segunda parte é bilíngue, no método fonético". ${ }^{35}$

Como mencionado, com a implantação do Estado Novo, as línguas das colônias formadas pela imigração europeia do século XIX foram banidas das escolas, mesmo aquelas em que as comunidades e ou consulados pagavam os/ as professores/as. Para lecionar era necessário ser brasileiro. A partir de 1937, em vez de bilíngues, as crianças deveriam saber apenas a língua portuguesa.

Essa medida repercutiu diretamente sobre os/as alunos/a e também sobre os/as professores/as, exemplo disso foi o que aconteceu com o professor Casemiro Stachurski na escola étnica organizada pelo núcleo de poloneses em Linha Batista, como aponta Lourenço. Em 1936, ele foi elogiado pelo Inspetor de Ensino no livro do Termo de Visitas, no documento consta o seguinte registro: "O inspetor teve boa impressão do professor, deixando votos de louvor, pelo serviço de nacionalização que está prestando a nossa grande Pátria, que também se tornou sua.." ${ }^{36}$ No entanto, com o acirramento da campanha de nacionalização do ensino Casemiro Stachurski foi afastado do cargo em 1938. No livro Termo de Visitas, fica registrado o ato de proibição quanto a sua permanência na escola:

[...] Casemiro Stachurski não voltará para Linha Batista, não porque é mau professor, pelo contrário, mas para fazer sentir que somos brasileiros e que as autoridades e as leis do Paiz devem ser respeitadas. O professor de Linha Batista, público ou particular, pelo que venho observando, só podemo-lo admitir brasileiro nato $[\ldots] .{ }^{37}$

A autora ainda afirma com base nos registros que os pais dos/as alunos/ as resistem à substituição do professor, ameaçando tirarem seus filhos/as da escola. 


\title{
OS CASTIGOS ESCOLARES: UMA DAS ESTRATÉGIAS DISCIPLINARES NAS ESCOLAS ÉTNICAS RURAIS
}

O castigo escolar tem atravessado os ambientes escolares há séculos, nas suas mais diversas configurações - físicos e morais - chegando à escola moderna, atingindo também as escolas étnicas rurais abordadas neste estudo.

Como recordam os irmãos Casemiro Demboski e Tereza Demboski Milak:

\begin{abstract}
$\mathrm{Na}$ escola tinha recreio, mas tinha castigo também, não é que nem hoje, a D. Iria [professora] andava sempre na escola com a vara de vime dizendo assim: Aqui, oh! O Inácio Kubasky também [outro professor]. A régua era comprida! O Inácio Kubasky tinha um filho chamado Francisco, ele andava na escola e fazia "arte", o Inácio agarrava ele e... váh nas costas, eu não sei quantas varadas. O Werpachowski [outro professor] não sovava mais com a régua, dava na palma da mão. Ele batia com essa régua, tinha que ir lá na frente, botar a mão para frente. Ajoelhar na porta da escola, pertinho da estrada, quando passava o pessoal, já viam que tem gente ajoelhado lá na porta. Do milho também, na escola tinha um banco chamado "banco piolhento", ela [a professora], às vezes revistava e se encontrasse piolho! - Vai lá naquele banco, fica meio dia sentado ali. Por isso apelidaram "banco do piolhento". ${ }^{38}$
\end{abstract}

Lembranças de surras, castigos e humilhações são muito presentes nas recordações desse tempo de escola. Os castigos escolares como parte integrante do processo pedagógico acompanharam as escolas em um longo processo. Todas as narrativas reportam a lembranças dos castigos, ou as crianças experimentando-os sob a ira de seus mestres, ou presenciando-os quando aplicados aos seus colegas.

Os irmãos Tereza e Casemiro recordam a respeito de um menino que era castigado porque fazia "artes". Podemos perguntar o que eram as "artes"? Pensamos que associada a essa ideia estão alguns dos "fazeres" das crianças, coisas que elas inventam, mesmo que seja para se distrair, olhando pela janela enquanto a professora explica as contas, ou escapando da escola para caçar passarinhos, práticas comuns das crianças da época apresentada; ou mesmo irritando-se com o colega, não trazendo as tarefas, ou não compreendendo a fala da professora. Tudo isso era motivo para os castigos.

Quem por acaso não cumprisse o que era solicitado pela/o professor/a era castigado. Por outro lado, como havia muitos castigos, podemos inferir que havia muita resistência ao ensino. Não fazer o que era solicitado poderia representar a não compreensão daquilo que a professora havia solicitado como 
também o entendimento de que a atividade ou conhecimento não era importante, pois, como recorda Antônio Zanette, "então, eu gostava de trabalhar, estudar pra quê? Naquele tempo não era como hoje, que quem estuda ganha." $\mathrm{Ou}$ Dona Maria de Luca, que argumenta: "eu gostava muito não de ir para a aula, gostava de brincar."

Mas, também havia aqueles que gostavam das letras, como Casimiro Tibincoski: "Eu gostava muito de leitura. Até hoje eu gosto. Eu era tão prático na leitura. Tinha uma biblioteca com 300 livros [em Linha Batista]. Uma parte foi fundada pelo falecido Padre Fracisco Chyliski e outra parte pelo casal Werpakoski. Aqueles 300 livros eu li e reli". ${ }^{39}$

As experiências aqui narradas são apenas algumas daquelas vivenciadas por ex-alunos/as das duas escolas étnicas analisadas, que representam parte da cultura escolar vivenciadas, reconstruídas por suas memórias. Muitos outros aspectos poderiam ser discutidos aqui, como as brincadeiras, os objetos escolares, a arquitetura, entre outros, mas estas questões não fazem parte do escopo deste artigo. Portanto, as experiências aqui problematizadas não dão conta do percurso desses alunos e alunas nas escolas étnicas rurais, muitos outros aspectos que deixaram marcas indeléveis na vida daqueles/as que passaram pelos bancos escolares ainda precisam ser aprofundados.

\section{CONSIDERAÇÕES FINAIS}

Inicialmente, as escolas étnicas funcionavam nas casas ou em locais cedidos pelas próprias comunidades e o quadro docente era formado por aqueles/as que dominavam a leitura e a escrita, na língua italiana ou polonesa. Os/as alunos/as que, em geral, estudavam até o $3^{\circ}$ ano primário, além de frequentarem as escolas assumiam atividades na roça, junto aos seus pais, ocasionando muitas faltas aos dias letivos.

Com o processo de nacionalização do ensino, principalmente no Estado Novo do Governo Vargas, os professores foram afastados e substituídos por docentes que falavam e ensinavam em língua portuguesa, no entanto, este processo não ocorreu sem resistência das comunidades, principalmente do núcleo de imigrantes poloneses. $\mathrm{O}$ fato de a escola ter reagido à expulsão do professor Casemiro Stachurski e, anos depois, ter homenageado o professor, escolhendo-o como patrono da escola, representam indícios dessa resistência. Ainda nos dias de hoje, a comunidade procura preservar a cultura polonesa promovendo atividades no Centro Cultural Octávia Búrigo Gaidzinski, criado pelos próprios moradores.

O processo de nacionalização pode ter representado para as escolas a melhoria da estrutura, afinal, o Estado passou a assumir a manutenção dos estabelecimentos e professores/as, no entanto, isso significou um forte impacto 
na trajetória e cultura destes estabelecimentos. Essas escolas abrigaram diferentes experiências, marcadas pelas culturas dos distintos grupos de imigrantes, mas, além disso, reconstruíram culturas dentro e fora do ambiente escolar.

\section{NOTAS}

1 Até o ano de 2010, foram publicados quatro cadernos tendo como autores/as: Giani Rabelo, Marli de Oliveira Costa, Gildo Volpato, Tatiane dos Santos Virtuoso, Leila Lourenço e Maria Dolores Denski. Os recursos para estas pesquisas e publicação foram obtidos por meio de editais de grupos de pesquisa lançados pela Pró-reitoria de Pós-graduação, pesquisa e extensão da Universidade do Extremo Sul Catarinense (Unesc).

2 O Centro da Memória da Educação do Sul de Santa Catarina (CEMESSC), virtual, está disponível em: <http://www.bib.unesc.net/muesc/muni_07.php>.

${ }^{3}$ MILANEZ, Pedro. Fundamentos históricos de Criciúma. Florianópolis: Ed. do autor, 1991.

${ }^{4}$ COSTA, Marli de Oliveira. Tudo isso eles contavam: memória dos moradores do bairro Santo Antônio, Criciúma (SC), 1880-2000. Criciúma: Secretaria de Educação Municipal, 2000.

${ }^{5}$ LOURENÇO, Leila. Escola Municipal Casemiro Stachurski: uma prática político pedagógica oficial forjada na interdição da cultura de uma comunidade escolar criciumense de origem polonesa. III Congresso Brasileiro de História da Educação, 2004, Curitiba. Anais eletrônicos. Disponível em: <http://www.sbhe.org.br/novo/congressos/cbhe3/Documentos/Individ/ Eixo3/222.pdf>. Acesso em: 6 fev. 2012.

${ }^{6}$ KREUTZ, Lúcio. Escolas étnicas no Brasil e a formação do Estado Nacional: A nacionalização compulsória das escolas dos imigrantes (1937-1945). Poésis, Tubarão, v. 3, n. 5, p. 71-84, jan./ jun. 2010 .

7 TEIVE, G.M.G. Uma vez normalista, sempre normalista: cultura escolar e produção de um habitus pedagógico (Escola Normal Catarinense - 1911/1935). Florianópolis: Insular, 2008.

${ }^{8}$ SANFELICE, José Luis. História, instituições escolares e gestores educacionais. Revista HISTEDBR On-line, Campinas, n. especial, p. 24, ago. 2006.

9 MEIHY, José Carlos Sebe Bom. Manual de História Oral. São Paulo: Ed. Loyola, 1996.

${ }^{10}$ THOMSON, Alistair. Histórias (co) movedoras: História Oral e estudos de migração. Revista Brasileira de História, São Paulo, v. 22, n. 44, p. 241-364, 2002.

${ }^{11}$ POLLAK, Michael. Memória, esquecimento, silêncio. Estudos Históricos, Rio de Janeiro, v. 2, n. 3, p. 3-15, 1989.

${ }^{12}$ ERRANTE, Antoinette. Mas afinal, a memória é de quem? Histórias Orais e modos de lembrar e contar. Revista da ASPHE, Pelotas, n. 8, p. 150, 2000.

${ }^{13}$ AMADO, Janaína. A culpa nossa de cada dia: ética e História Oral. Revista do Programa de Estudos Pós-Graduados em História e do Departamento de História, São Paulo, n. 15, p. 145-155, abr. 1997.

${ }^{14}$ ERRANTE, op. cit., p.146.

${ }^{15}$ LOPES, Eliane Marta Teixeira; GALVÃO, Ana Maria de Oliveira. História da Educação. Rio de Janeiro: DP\&A, 2001. p. 93. 
${ }^{16}$ BOSI, Ecléa. Memória e Sociedade: lembrança de velhos. 2 ed. São Paulo: EDUSP, 1987.

${ }^{17}$ KREUTZ, Lúcio. Escolas comunitárias de imigrantes no Brasil: instâncias de coordenação e estruturas de apoio. Revista Brasileira de Pós-graduação e Pesquisa em Educação, São Paulo, n. 15, p. 159, nov/dez. 2000.

${ }^{18}$ DALL'ALBA, João Leonir. Imigração italiana em Santa Catarina: documentários. Caxias do Sul; Porto Alegre; Florianópolis: Ed. da UDUCS; EST; Lunardelli, 1983.

${ }^{19}$ RABELO, Giani; LOURENÇO, Leila; COSTA, Marli de Oliveira. A escola na colina: grupo escolar núcleo Hercílio Luz (1905-2002). Criciúma: UNESC, 2003.

${ }^{20}$ Casimiro Tibincoski, entrevista concedida a Tatiane dos Santos Virtuoso, em 17/2/2003.

${ }^{21}$ Sobre isso ver, SIROTA, Régine. Emergência de uma sociologia da infância: evolução do objeto e do olhar. Cadernos de Pesquisa, São Paulo, Fundação Carlos Chagas, Editora dos autores associados, n. 112, 2001.

${ }^{22}$ NORA, Pierre. Entre história e memória: a problemática dos lugares. Projeto História, São Paulo, v. 10, p. 7-28, 1993.

${ }^{23}$ THOMSON, Alistair. Recompondo a memória: questões sobre a relação entre História Oral e as memórias. Projeto História, São Paulo, n. 15, p. 57, abr. 1997.

${ }^{24}$ ROLNIK, Raquel. Lei política: a construção dos territórios urbanos. Projeto História, São Paulo, v.18, p. 135, mai. 1999.

${ }^{25}$ VIÑAO FRAGO, Antônio. El espacio y el tiempo escolares como objeto histórico. Contemporaneidade e Educação. Instituto de Estudos da Cultura e Educação Continuada (IEC), Rio de Janeiro, n. 7, 2000.

${ }^{26}$ Casimiro Tibincoski, entrevista concedida a Tatiane dos Santos Virtuoso, em 17 fev. 2003.

${ }^{27}$ Casimiro Tibincoski, entrevista concedida a Tatiane dos Santos Virtuoso, em 17 fev. 2003.

${ }^{28}$ Maria de Luca Thomasi, entrevista concedida a Tatiane dos Santos Virtuoso e Andreane Fátima Tecchio Motta, em 29 maio 2002.

${ }^{29}$ Maria Dinca Dal Toé, entrevista concedida a Tatiane dos Santos Virtuoso e Andreane Fátima Tecchio Motta, em 25 maio 2002.

${ }^{30}$ LINS DE BARROS, Myrian Moraes. Memória e família. Estudos Históricos, Rio de Janeiro, v. 2 , n. 3, p. $34,1989$.

${ }^{31}$ Antônio Zanette, entrevista concedida a Andreane Motta e Tatiane dos Santos Virtuoso, em 25 jun. 2002.

${ }^{32}$ Casemiro Demboski e Tereza Demboski Milak, entrevista concedida a Tatiane dos Santos Virtuoso e Andreane Fátima Tecchio Motta, em 2002.

${ }^{33}$ Alberto Rzatki, entrevista concedida a Tatiane dos Santos Virtuoso e Andreane Fátima Tecchio Motta, em 10 out. 2002.

${ }^{34}$ Pelaguia Marchiski Bartosiak, entrevista concedida a Tatiane dos Santos Virtuoso e Andreane Fátima Tecchio Motta, em 2 set. 2002.

${ }^{35}$ KREUTZ, op. cit., p. 170.

${ }^{36}$ LOURENÇO, Leila. Lembranças, registros e percepções do processo de ensino e aprendizagem. In: RABELO, Giane et al. Escola Casemiro Stachurski: das aulas particulares/ comunitárias ao ensino público municipal. Criciúma: UNESC, 2005. 
${ }^{37}$ Ibidem, p. 40.

${ }^{38}$ Casemiro Demboski e Tereza Demboski Milak, entrevista concedida a Tatiane dos Santos Virtuoso e Andreane Fátima Tecchio Motta, em 2002.

${ }^{39}$ Casimiro Tibincoski, entrevista concedida a Tatiane dos Santos Virtuoso, em 17 fev. 2003.

Artigo recebido em maio de 2012. Aceito em abril de 2013. 